\title{
Prognostic Effect of Preoperative Apolipoprotein B Level in Surgical Patients with Renal Clear Cell Carcinoma
}

\section{Kun Wang}

department of surgical urology, Third Affiliated Hospital of Soochow University

\section{Tingchun Wu}

Third Affiliated Hospital of Soochow University

\section{Yiming Chen}

Third Affiliated Hospital of Soochow University

\section{Guanglai Song}

Third Affiliated Hospital of Soochow University

\section{Xiaozhou He}

Third Affiliated Hospital of Soochow University

zhen chen ( $\nabla$ 866abc@sina.cn )

Third Affiliated Hospital of Soochow University

\section{Research article}

Keywords: ApoB, clear cell renal cell carcinoma, preoperative, prognosis

Posted Date: August 15th, 2019

DOl: https://doi.org/10.21203/rs.2.13038/v1

License: (1) This work is licensed under a Creative Commons Attribution 4.0 International License. Read Full License 


\section{Abstract}

Objectives To assess the prognostic value of preoperative apolipoprotein B level in surgical patients with renal clear cell carcinoma (ccRCC). Materials and Methods The study included $308 \mathrm{ccRCC}$ patients receiving radical or partial nephrectomy between 2003 and 2012 in our center. The correlations among the preoperative ApoB, clinico -pathological parameters, and overall survival (OS) were evaluated. Results A total of 193 men $(62.9 \%)$ and 114 women $(37.1 \%)$ with ccRCC underwent radical or partial nephrectomy were enrolled in the present study. The OS at five years after operation was $90.6 \%$ for all patients, $87.4 \%$ for the lower ApoB group, and $97.0 \%$ for the higher ApoB group. The CSS at 5 years after surgery was 90.2\% for all patients, $86.7 \%$ for the lower ApoB group, and 97.0\% for the higher ApoB group. A higher ApoB level was related to a better OS and CSS in ccRCC patients $(P=0.001$ and $P<0.001$, respectively). In multivariate analysis, age $>60(P=0.008$ and $P=0.023)$, lower Apo $B$ level $(P=0.019$ and $P=0.018)$, were independent prognostic factors for OS and CSS, respectively. Conclusions In the Apo apolipoprotein family, the preoperative ApoB level has an important clinical significance for predicting the prognosis survival rate of the ccRCC patients.

\section{Background}

Renal cell cancer is a common kind of urinary tumor and accounts for 2-3\% of all cancers[1]. More than $80 \%$ of them are clear cell carcinoma, and other histological types are very rare[ 2]. Surgery has been the benchmark for the treatment of RCC[ 3]. However, preoperative judgment of the patient's prognosis is very important for patients and clinicians[ 4]. Although there are already some indicators that could predict the prognosis[ 5, 6], such as TNM stage, Fuhrman grade and CRP/Alb ratio, simple biomarkers are still lacking for early diagnosis and the judgment of prognosis in clinical practice.

Apolipoprotein ApoB is a newly discovered potential tumor marker that plays an important role in lipoprotein metabolism and participates in the reverse transport of cholesterol[ 7]. There are different degrees of ApoB elevation in the patient's serum of liver cancer, breast cancer and ovarian cancer[ 8, 9]. The changes of ApoB level had an important value for the prognosis of the above tumors. Therefore, in this study we aim to explore the prognostic performance of the preoperative ApoB level in Chinese patients with ccRCC.

\section{Methods}

\section{Patients}

The data of 414 ccRCC patients which underwent radical or partial nephrectomy in The Third Affiliated Hospital of Soochow University between 2003 and 2012 were collected in our study. Of all 414 patients, 106 patients were excluded: 36 patients had concomitant chronic diseases, including diabetes, hyperlipidemia and metabolic syndrome; 17 patients had been lost in the follow-up time; 17 patients' information on were incomplete and unclear; 36 patients had received drug therapy previously. Finally, the 308 patients were identified for related analysis.

\section{Clinical and laboratory data}

The characteristics and information of each patient included in our study were summarized: age at surgery, gender, TNM stage, Fuhrman grade, tumor necrosis and tumor size, LVI and LDH and AKP. The 2010 renal TNM stage by AJCC was adopt[10]. Fuhrman grade was recommended by WHO in 1997. Tumor necrosis was defined as microscopic 
coagulative necrosis[ 11]. The data of LVI, LDH and AKP were obtained within 1 week before surgery. All of the above data above were retrieved from Medical records inquiry system of The Third Affiliated Hospital of Soochow University.

\section{Statistical analyses}

For the description of clinical and pathological characteristics of patients, categorical variables were presented as numbers and percentages, continuous variables were allocated in groups according to the optimal cut-off value. Receiver operating characteristics (ROC) analysis was done to identify the cutoff point of continuous variables. OS was calculated from date of surgery to individuals' death of any cause or last follow-up. The OS rates were calculated using the Kaplan-Meier method, and compared using the log-rank test. Univariate analysis of the potential factors related to survival was conducted with the help of Mantel-Cox regression methodology. The Cox proportional hazards model was used for the multivariate analysis to identify independent prognostic factors associated with OS. ROC analysis was also used to measure and compare the areas under the curve (AUC). The Chi square test was used to detect the differences between groups. All statistical tests were two-sided and a P-value $<0.05$ was considered statistically significant. All data analyses were performed with SPSS Statistics 17.0.

\section{Results}

A total of 193 men (62.9\%) and 114 women (37.1\%) with CCRCC underwent radical or partial nephrectomy were enrolled in the present study. The mean age of the patient group was 56.29 years (SD \pm 11.63 ; range 24-80). The mean postoperative follow-up was 69.17 (range 1-151) months. The mean and median preoperative value of the ApoB was $0.941 \pm 0.282$ (range $0.41-2.73$ ) and 0.92 . The cutoff value of $A$ poB divided the patients into two groups (ApoB $\leq 1.015$ and $A p o B>1.015)$. Table 1 showed the relationships between ApoB levels and the clinicopathological characteristics of the all CCRCC patients included in the study. There were no significant differences with regard to age, sex, tumor size, tumor stage, lymph node stage, Fuhrman grade, the presence of Tumor necrosis, lymphovascular invasion, LDH and AKP levels between the two groups. Therefore, we did not conduct the propensity score-matched analysis for ApoB. Figure 1 shows the Kaplan-Meier survival curve for CSS and OS according to ApoB level. The OS at five years after operation was $90.6 \%$ for all patients, $87.4 \%$ for the lower ApoB group, and $97.0 \%$ for the higher ApoB group. The CSS at 5 years after surgery was $90.2 \%$ for all patients, $86.7 \%$ for the lower ApoB group, and $97.0 \%$ for the higher ApoB group. A higher ApoB level was related to a better OS and CSS in cCRCC patients $(P=0.001$ and $P<0.001$, respectively). Univariate analysis indicated that age $>60(P=0.002$ and $P=0.004)$, higher pathological $T$ stage $(P<0.001$ and $P<$ $0.001)$, higher pathological $N$ stage $(P<0.001$ and $P<0.001)$, higher Fuhrman grade $(P<0.001$ and $P<$ $0.001)$, larger Tumor size $(P<0.001$ and $P<0.001)$, present of Tumor necrosis $(P<0.001$ and $P<0.001)$, present of $L V I(P<0.001$ and $P<0.001)$, lower Apo $B$ level $(P=0.003$ and $P=0.002)$, higher $L D H$ level $(P=$ 0.001 and $P<0.001)$, higher AKP level $(P<0.001$ and $P<0.001)$ were poor survival for OS (Table 2$)$ and CSS (Table 3), respectively. In multivariate analysis, age $>60(P=0.008$ and $P=0.023)$, lower Apo $B$ level $(P=0.019$ and $P=0.018)$, were independent prognostic factors for OS (Table 2$)$ and CSS (Table 3$)$, respectively.

\section{Discussion}


For renal clear cell carcinoma, a simple biomarker for early diagnosis and prognosis is still lacking in clinical practice. Through our research, it is found that apolipoprotein ApoB is of great significance.

Previous literature[ 12] reported that ApoB, SLC3A1, SCD5, and AQP1 genes could be used as prognostic biomarkers for renal clear cell carcinoma, and the four genes had different powers that judged the prognosis. However, the specific effect of ApoB was not illuminated.

Renal clear cell carcinoma is a malignant tumor composed of cells whose cytoplasm is transparent[ 13]. And cancer cells are rich in cholesterol and cholesterol esters[ 14, 15]. In 1987, it was firstly reported by Gcbhard et al[ 15]. that the levels of cholesterol and cholesterol esters in renal cell carcinoma were higher than those in normal kidney tissues. Subsequently, some experimental studies also confirmed the above result and further found that the level of cholesterol was positively associated with the malignant degree of cancer cells[ 16, 17]. However, the cholesterol levels in advanced biological cells are maintained in a fairly narrow range, and the negative feedback regulation of endogenous cholesterol synthesis play an important role in maintaining the cholesterol metabolic balance[ 18, 19]. And the biological effect of serum cholesterol was related with low-density lipoprotein (LDL)[ 20]. It was manifested by the fact that about two-thirds of endogenous cholesterol were transported by LDL[21]. Therefore, we concluded that if the cholesterol level in renal cancer tissues increased significantly with the malignant degree elevating, the negative feedback regulation could inhibit the synthesis and transport of endogenous cholesterol, and this indirectly resulted that the level of LDL decreased.

In our study, patients with the high level of preoperative ApoB had a higher survival rate than those with the low level of preoperative ApoB. We considered this was mainly related with the level of LDL metabolism. ApoB is an important structural component of LDL[22]. According to the above analysis, the negative feedback regulation caused by the increasing cholesterol level of renal clear cell carcinoma tissue with the malignant degree elevating indirectly leaded to a decrease in LDL levels, which inevitably resulted in a decrease in serum ApoB levels. In other words, the level of ApoB ultimately reflected the overall prognosis of tumor patients by indirectly reflecting the malignant degree of the tumor.

Apolipoprotein ApoB acts indirectly by reflecting the LDL levels, so why not to directly adopt the LDL levels as the prognostic index? The reasons maybe are as followings: the small, dense low-density lipoprotein (sd-LDL) is difficult to detect in the blood[ 23], but as its structural component ApoB can be simply detected in the blood. Thus, apolipoprotein ApoB has become a more advantageous detection index by more comprehensively reflecting the LDL level.

In addition, we considered that in a nutritional perspective patients with the high level of preoperative ApoB should also have a higher survival rate. The reasons were as followings: the level of ApoB represented the nutritional level of the patient to some extent[ 24]. And the nutritional level of the patient determined the body resistance[ 25]. When the body resistance increased, the capability of tumor tolerance and the prognosis survival rate also elevated.

Some trials documented that in the apolipoprotein family Apo A-I and ApoL1 had an anti-tumor effect[ 26]. But the mechanism of the two were different. Recently, researchers used ApoA-I mimetic peptides to observe the association between ApoA-I and ovarian cancer cells[27]. ApoA-I mimetic peptides reduced viability and proliferation of ID8 cells and cis-platinum -resistant human ovarian cancer cells, and decreased ID-8 cell-mediated tumor burden in C57BL/6J mice when administered subcutaneously or orally. However, ApoL1 could play an anti-tumor role by the p53-associated autophagy in the Apo apolipoprotein family[ 28]. The Study had shown that p53 could stimulate the expression of ApoL1. Then the high level of intracellular ApoL1 activate the transcription of LC3-II which induces the autophagy of cancer cells.

Compared with the ApoB, though Apo A-I and ApoL1 had an anti-tumor effect, there were no related experiment studies confirm their effect in renal clear cell carcinoma. Moreover, no clinical trials revealed the high level of Apo A-I and ApoL1 was associated with the high survival rate of renal cancer. However, the relation between the two and the prognosis of renal clear cell carcinoma could be researched in the future. 
Our research has several shortcomings. Firstly, it is only a single-center study. In the future, we would collect more samples by multi-centers cooperation to carry out related research. Secondly, we only include renal clear cell carcinoma, and we would further explore the predictive significance of ApoB in other types of kidney cancer in the future.

\section{Conclusion}

Conclusively, in the Apo apolipoprotein family, the preoperative ApoB level has an important clinical significance for predicting the prognosis survival rate of the ccRCC patients.

\section{Declarations}

\section{Ethics approval and consent to participate}

We declare that our research has been performed in accordance with the Declaration of Helsinki and has been approved by the ethics committee of the Third Affiliated Hospital of Soochow University.

\section{Consent to publish}

We confirm that we have obtained the consent of the persons for publication.

\section{Availability of data and materials}

We ensure that materials described in the manuscript, including all relevant raw data, will be freely available to any scientist wishing to use them for non-commercial purposes, without breaching participant confidentiality..

\section{Competing interests}

We declare that they have no competing interests

\section{Funding}

We have no funding supports.

\section{Authors Contributions}

WK and CZ conceived and designed the study. W TC and C YM performed the study. provided the mutants. WK wrote the paper. S GL and H XZ reviewed and edited the manuscript. All authors read and approved the manuscript.

\section{Acknowledgements}

All contributors meet the criteria for authorship.

\section{Abbreviations:}

ccRCC: renal clear cell carcinoma, Apo B: Apolipoprotein B, OS: overall survival, LVI : lymphovascular invasion, AKP: alkaline phosphatase, LDH: lactate dehydrogenase, sd-LDL: the small, dense low-density lipoprotein, ROC: Receiver operating characteristics, TNM:tumor-node-metastasis, CRP/Alb: the C-reactive protein/Albumin ratio, AUC: area under the curves, CSS: Cancer-Specific Survival.

\section{References}



Carcinoma: Alternative Nephron-Sparing Treatment Options for Small Renal Masses, a Systematic Review. Journal of endourology / Endourological Society 2017, 31(10):963-975.

Pierorazio PM, Hyams ES, Tsai S, Feng Z, Trock BJ, Mullins JK, Johnson PT, Fishman EK, Allaf ME: Multiphasic enhancement patterns of small renal masses $(</=4 \mathrm{~cm})$ on preoperative computed tomography: utility for distinguishing subtypes of renal cell carcinoma, angiomyolipoma, and oncocytoma. Urology 2013, 81(6):1265-1271.

3. Kunath F, Schmidt S, Krabbe LM, Miernik A, Dahm P, Cleves A, Walther M, Kroeger N: Partial nephrectomy versus radical nephrectomy for clinical localised renal masses. The Cochrane database of systematic reviews 2017, 5:CD012045.

4. Zisman A, Patard JJ, Raz O, Klatte T, Haifler M, Mendlovic S, Sandbank J, Belldegrun AS, Lindner A, Leibovici $\mathrm{D}$ et al: Sex, age, and surgeon decision on nephron-sparing surgery are independent predictors of renal masses with benign histologic findings--a multicenter survey. Urology 2010, 76(3):541-546. Nephrometry Score: A Preoperative Risk Factor Predicting the Fuhrman Grade of Clear-Cell Renal Carcinoma. Journal of Cancer 2017, 8(18):3725-3732.

Chen Z, Shao Y, Fan M, Zhuang Q, Wang K, Cao W, Xu X, He X: Prognostic significance of preoperative Creactive protein: albumin ratio in patients with clear cell renal cell carcinoma. International journal of clinical and experimental pathology 2015, 8(11):14893-14900.

Klos KL, Sing CF, Boerwinkle E, Hamon SC, Rea TJ, Clark A, Fornage M, Hixson JE: Consistent effects of genes involved in reverse cholesterol transport on plasma lipid and apolipoprotein levels in CARDIA participants. Arteriosclerosis, thrombosis, and vascular biology 2006, 26(8):1828-1836.

8. Gudowska M, Gruszewska E, Cylwik B, Panasiuk A, Filisiak R, Szmitkowski M, Chrostek L: Serum Sialic Acid Concentration and Content in ApoB-Containing Lipoproteins in Liver Diseases. Clinical laboratory 2016, 62(6):1069-1074.

9. Borgquist S, Butt T, Almgren P, Shiffman D, Stocks T, Orho-Melander M, Manjer J, Melander O: Apolipoproteins, lipids and risk of cancer. International journal of cancer Journal international du cancer 2016 , 138(11):2648-2656.

10. Martinez-Salamanca JI, Huang WC, Millan I, Bertini R, Bianco FJ, Carballido JA, Ciancio G, Hernandez C, Herranz F, Haferkamp A et al: Prognostic impact of the 2009 UICC/AJCC TNM staging system for renal cell carcinoma with venous extension. European urology 2011, 59(1):120-127.

11. Ito K, Seguchi K, Shimazaki H, Takahashi E, Tasaki S, Kuroda K, Sato A, Asakuma J, Horiguchi A, Asano T: Tumor necrosis is a strong predictor for recurrence in patients with pathological T1a renal cell carcinoma. Oncology letters 2015, 9(1):125-130.

12. Song J, Liu YD, Su J, Yuan D, Sun F, Zhu J: Systematic analysis of alternative splicing signature unveils prognostic predictor for kidney renal clear cell carcinoma. Journal of cellular physiology 2019.

13. Wu F, Zhao ZH, Ding ST, Wu HH, Lu JJ: High mobility group box 1 protein is methylated and transported to cytoplasm in clear cell renal cell carcinoma. Asian Pacific journal of cancer prevention : APJCP 2013, 14(10):5789-5795.

14. Drabkin HA, Gemmill RM: Cholesterol and the development of clear-cell renal carcinoma. Current opinion in pharmacology 2012, 12(6):742-750.

15. Gebhard RL, Clayman RV, Prigge WF, Figenshau R, Staley NA, Reesey C, Bear A: Abnormal cholesterol metabolism in renal clear cell carcinoma. Journal of lipid research 1987, 28(10):1177-1184.

16. Tugnoli V, Poerio A, Tosi MR: Phosphatidylcholine and cholesteryl esters identify the infiltrating behaviour of a clear cell renal carcinoma: 1H, 13C and 31P MRS evidence. Oncology reports 2004, 12(2):353-356. 
17. Saito K, Arai E, Maekawa K, Ishikawa M, Fujimoto H, Taguchi R, Matsumoto K, Kanai Y, Saito Y: Lipidomic Signatures and Associated Transcriptomic Profiles of Clear Cell Renal Cell Carcinoma. Scientific reports 2016, 6:28932.

18. Mancini M, Postiglione A, di Marino L: Feedback regulation of metabolism by dietary constituents: lipids. Nutrition and metabolism 1977, 21(1-3):13-25.

19. Bi Y, Shi X, Zhu J, Guan X, Garbacz WG, Huang Y, Gao L, Yan J, Xu M, Ren S et al: Regulation of Cholesterol Sulfotransferase SULT2B1b by Hepatocyte Nuclear Factor 4alpha Constitutes a Negative Feedback Control of Hepatic Gluconeogenesis. Molecular and cellular biology 2018, 38(7).

20. Konrad E, Guralp O, Shaalan W, Elzarkaa AA, Moftah R, Alemam D, Malik E, Soliman AA: Correlation of elevated levels of lipoprotein(a), high-density lipoprotein and low-density lipoprotein with severity of preeclampsia: a prospective longitudinal study. Journal of obstetrics and gynaecology : the journal of the Institute of Obstetrics and Gynaecology 2019:1-6.

21. Goulinet S, Chapman MJ: Plasma LDL and HDL subspecies are heterogenous in particle content of tocopherols and oxygenated and hydrocarbon carotenoids. Relevance to oxidative resistance and atherogenesis. Arteriosclerosis, thrombosis, and vascular biology 1997, 17(4):786-796.

22. Yu Q, Zhang Y, Xu CB: Apolipoprotein B, the villain in the drama? European journal of pharmacology 2015, 748:166-169.

23. Satoh N, Wada H, Ono K, Yamakage H, Yamada K, Nakano T, Hattori M, Shimatsu A, Kuzuya H, Hasegawa K: Small dense LDL-cholesterol relative to LDL-cholesterol is a strong independent determinant of hypoadiponectinemia in metabolic syndrome. Circulation journal : official journal of the Japanese Circulation Society 2008, 72(6):932-939.

24. Royo-Bordonada MA, Garces C, Gorgojo L, Martin-Moreno JM, Lasuncion MA, Rodriguez-Artalejo F, Fernandez O, de Oya M, Four Provinces S: Saturated fat in the diet of Spanish children: relationship with anthropometric, alimentary, nutritional and lipid profiles. Public health nutrition 2006, 9(4):429-435.

25. Yu SY, Ryu HK, Park HJ, Choi YJ, Huh KB, Kim WY: Adiponectin gene SNP 276G --> T, nutrient intakes, and cardiovascular disease risk in Korean type 2 DM patients. Nutrition research and practice 2007, 1(4):363-370.

26. Liu X, Zheng W, Wang W, Shen H, Liu L, Lou W, Wang X, Yang P: A new panel of pancreatic cancer biomarkers discovered using a mass spectrometry-based pipeline. British journal of cancer 2017, 117(12):1846-1854.

27. Gao F, Chattopadhyay A, Navab M, Grijalva V, Su F, Fogelman AM, Reddy ST, Farias-Eisner R: Apolipoprotein A-I mimetic peptides inhibit expression and activity of hypoxia-inducible factor-1alpha in human ovarian cancer cell lines and a mouse ovarian cancer model. The Journal of pharmacology and experimental therapeutics 2012, 342(2):255-262.

28. Wan G, Zhaorigetu S, Liu Z, Kaini R, Jiang Z, Hu CA: Apolipoprotein L1, a novel Bcl-2 homology domain 3only lipid-binding protein, induces autophagic cell death. The Journal of biological chemistry 2008, 283(31):21540-21549.

\section{Tables}

Table 1. The clinicopathological characteristics of patients, and correlation of Apo B with the clinicopathological characteristics. 


\begin{tabular}{|c|c|c|c|c|}
\hline \multirow[t]{2}{*}{ iable } & \multicolumn{4}{|c|}{ No. of Patients (\%) } \\
\hline & $(\mathrm{n}=307)$ & $\begin{array}{l}\text { Apo } B \leq 1.015 \\
(n=206)\end{array}$ & $\begin{array}{l}\text { Apo B > } 1.015 \\
(n=101)\end{array}$ & $P$ value \\
\hline (years) & & & & 0.603 \\
\hline 0 & $179(58.3)$ & $118(57.3)$ & $61(60.4)$ & \\
\hline \multirow[t]{2}{*}{0} & $128(41.7)$ & $88(42.7)$ & $40(39.6)$ & \\
\hline & & & & 0.530 \\
\hline e & $193(62.9)$ & $132(64.1)$ & $61(60.4)$ & \\
\hline ıale & $114(37.1)$ & $74(35.9)$ & $40(39.6)$ & \\
\hline \multirow[t]{4}{*}{ age } & & & & 0.194 \\
\hline & $251(81.8)$ & $166(80.6)$ & $85(84.2)$ & \\
\hline & $32(10.4)$ & $20(9.7)$ & $12(11.9)$ & \\
\hline & $24(7.8)$ & $20(9.7)$ & $4(4.0)$ & \\
\hline \multirow[t]{3}{*}{;age } & & & & 0.843 \\
\hline & $297(96.7)$ & 199 (96.9) & $98(97.0)$ & \\
\hline & $10(3.3)$ & $7(3.4)$ & $3(3.0)$ & \\
\hline \multirow[t]{5}{*}{ rman grade } & & & & 0.859 \\
\hline & $64(21.5)$ & $43(21.6)$ & $21(21.4)$ & \\
\hline & $153(51.5)$ & $101(50.8)$ & $52(53.1)$ & \\
\hline & $63(21.2)$ & $42(21.1)$ & $21(21.4)$ & \\
\hline & $17(5.7)$ & $13(6.5)$ & $4(4.1)$ & \\
\hline \multirow[t]{3}{*}{ Ior size, $\mathrm{cm}$} & & & & 0.050 \\
\hline & $194(63.6)$ & $122(59.8)$ & $72(71.3)$ & \\
\hline & $111(36.4)$ & $82(40.2)$ & $29(28.7)$ & \\
\hline lor necrosis & & & & 0.216 \\
\hline ent & $280(91.2)$ & $185(89.8)$ & $95(94.1)$ & \\
\hline \multirow[t]{2}{*}{ sent } & $27(8.8)$ & $21(10.2)$ & $6(5.9)$ & \\
\hline & & & & 0.320 \\
\hline ent & $289(94.1)$ & $192(93.2)$ & $97(96.0)$ & \\
\hline sent & $18(5.9)$ & $14(6.8)$ & $4(4.0)$ & \\
\hline $\mathrm{I}(\mathrm{U} / \mathrm{L})$ & & & & 0.542 \\
\hline$: 5$ & $301(98.4)$ & $202(98.1)$ & $99(99.0)$ & \\
\hline j & $5(1.6)$ & $4(1.9)$ & $1(1.0)$ & \\
\hline ' $(\mathrm{U} / \mathrm{L})$ & & & & 0.358 \\
\hline ;0 & $292(95.4)$ & $195(94.7)$ & $97(97.0)$ & \\
\hline ) & $14(4.6)$ & $11(5.3)$ & $3(3.0)$ & \\
\hline
\end{tabular}

* indicates that the difference was statistically significant

Abbreviation: LVI lymphovascular invasion, AKP, alkaline phosphatase, LDH lactate dehydrogenase 
Table 2. Univariate and Multivariate Cox Proportional Analysis with Overall Survival.

\begin{tabular}{|c|c|c|c|c|}
\hline \multirow[t]{2}{*}{ riable } & \multicolumn{2}{|c|}{ Univariate analysis } & \multicolumn{2}{|c|}{ Multivariate analysis } \\
\hline & HR (95 \% CI) & $p$ value & HR (95 \% CI) & $p$ value \\
\hline e (years) & & $0.002 *$ & & 0.008* \\
\hline $0 \mathrm{VS} \leq 60$ & $2.81(1.46-5.41)$ & & $2.87(1.32-6.25)$ & \\
\hline $\mathrm{x}$ & & 0.109 & & \\
\hline ile VS Female & $1.80(0.88-3.67)$ & & & \\
\hline ;tage & & $<0.001 *$ & & 0.081 \\
\hline & reference & & reference & \\
\hline & 4.67 (2.06-10.57) & $<0.001 *$ & $1.792(0.66-4.85)$ & 0.251 \\
\hline & $18.50(9.03-37.87)$ & $<0.001 *$ & 3.50 (1.16- 10.59) & $0.026 *$ \\
\hline stage & & $<0.001 *$ & & 0.060 \\
\hline IS 0 & $7.83(3.25-18.86)$ & & $3.91(0.94-16.21)$ & \\
\hline hrman grade & & $<0.001 *$ & & 0.251 \\
\hline & reference & & reference & \\
\hline & $6.39(0.85-48.23)$ & 0.072 & $6.02(0.78-46.34)$ & 0.085 \\
\hline & $12.66(1.65-97.16)$ & $0.015^{*}$ & $8.22(1.01-66.94)$ & 0.049* \\
\hline & $35.39(4.42-283.19)$ & $0.001 *$ & $4.33(0.43-43.68)$ & 0.214 \\
\hline mor size, $\mathrm{cm}$ & & $<0.001 *$ & & 0.227 \\
\hline$j \mathrm{VS} \leq 5$ & $4.98(2.47-10.04)$ & & $1.78(0.70-4.55)$ & \\
\hline mor necrosis & & $<0.001 *$ & & 0.343 \\
\hline esent VS Absent & 3.95 (1.96- 7.97) & & $1.50(0.65-3.51)$ & \\
\hline $\mathrm{I}$ & & $<0.001 *$ & & 0.263 \\
\hline esent VS Absent & 7.62 (3.59-16.17) & & $1.95(0.61-6.15)$ & \\
\hline o B & & $0.003^{*}$ & & 0.019* \\
\hline $.23 \mathrm{VS}>1.23$ & 4.89 (1.73- 13.81) & & $4.30(1.27-14.59)$ & \\
\hline IH (U/L) & & $0.001 *$ & & 0.201 \\
\hline $45 \mathrm{VS} \leq 245$ & $7.28(2.22-23.89)$ & & $2.83(0.57-13.91)$ & \\
\hline $\mathrm{P}(\mathrm{U} / \mathrm{L})$ & & $<0.001 *$ & & 0.376 \\
\hline $30 \mathrm{VS} \leq 130$ & 7.38 (3.19-17.09) & & $1.75(0.50-6.04)$ & \\
\hline
\end{tabular}

* indicates that the difference was statistically significant

Abbreviation: LVI lymphovascular invasion, AKP alkaline phosphatase, LDH lactate dehydrogenase.

Table 3. Univariate and Multivariate Cox Proportional Analysis with Cancer-Specific Survival. 


\begin{tabular}{|c|c|c|c|c|}
\hline \multirow[t]{2}{*}{ ible } & \multicolumn{2}{|c|}{ Univariate analysis } & \multicolumn{2}{|c|}{ Multivariate analysis } \\
\hline & HR(95 \% CI) & $p$ value & HR(95 \% CI) & $p$ value \\
\hline$\overline{\text { years) }}$ & & 0.004* & & $0.023 *$ \\
\hline $\mathrm{VS} \leq 60$ & $2.72(1.38-5.38)$ & 0.223 & $2.59(1.14-5.88)$ & \\
\hline $\begin{array}{l}\text { VS Female } \\
\text { ge }\end{array}$ & $1.55(0.82-2.95)$ & $<0.001 *$ & & 0.062 \\
\hline & reference & & reference & \\
\hline & $6.16(2.80-13.56)$ & $<0.001 *$ & $2.03(0.72-5.76)$ & 0.183 \\
\hline & $28.32(14.30-56.08)$ & $<0.001 *$ & 3.85 (1.24- 11.99) & $0.020 *$ \\
\hline gge & & $<0.001 *$ & & $0.063 *$ \\
\hline 0 & $7.83(3.25-18.87)$ & & $4.53(1.25-16.43)$ & \\
\hline man grade & & $<0.001 *$ & & 0.331 \\
\hline & reference & & reference & \\
\hline & $2.34(0.68-8.02)$ & 0.177 & $5.18(0.66-40.47)$ & 0.117 \\
\hline & $4.70(1.36-16.24)$ & $0.014^{*}$ & $6.98(0.84-58.01)$ & 0.072 \\
\hline & $13.07(3.54-48.31)$ & $<0.001 *$ & $3.82(0.38-38.54)$ & 0.256 \\
\hline or size, $\mathrm{cm}$ & & $<0.001 *$ & & 0.154 \\
\hline$\tau \mathrm{S} \leq 5$ & $6.35(2.88-13.98)$ & & $2.11(0.76-5.90)$ & \\
\hline or necrosis & & $<0.001 *$ & & 0.182 \\
\hline ənt VS Absent & $4.71(2.31-9.58)$ & & $1.78(0.76-4.14)$ & \\
\hline & & $<0.001 *$ & & 0.229 \\
\hline ənt VS Absent & 8.35 (3.89- 17.89) & & $2.04(0.64-6.51)$ & \\
\hline B & & $0.002 *$ & & $0.018 *$ \\
\hline $3 \mathrm{VS} \leq 1.23$ & $6.47(1.98-21.12)$ & & $5.92(1.36-25.74)$ & \\
\hline$(\mathrm{U} / \mathrm{L})$ & & $<0.001 *$ & & 0.227 \\
\hline$i V S \leq 245$ & $8.29(2.53-27.20)$ & & $2.66(0.54-13.06)$ & \\
\hline $\mathrm{U} / \mathrm{L})$ & & $<0.001 *$ & & 0.146 \\
\hline VS $\leq 130$ & 7.38 (3.19-17.09) & & $2.17(0.76-6.18)$ & \\
\hline
\end{tabular}

* indicates that the difference was statistically significant Abbreviation: LVI lymphovascular invasion, AKP alkaline phosphatase, LDH lactate dehydrogenase, 
Figures

A

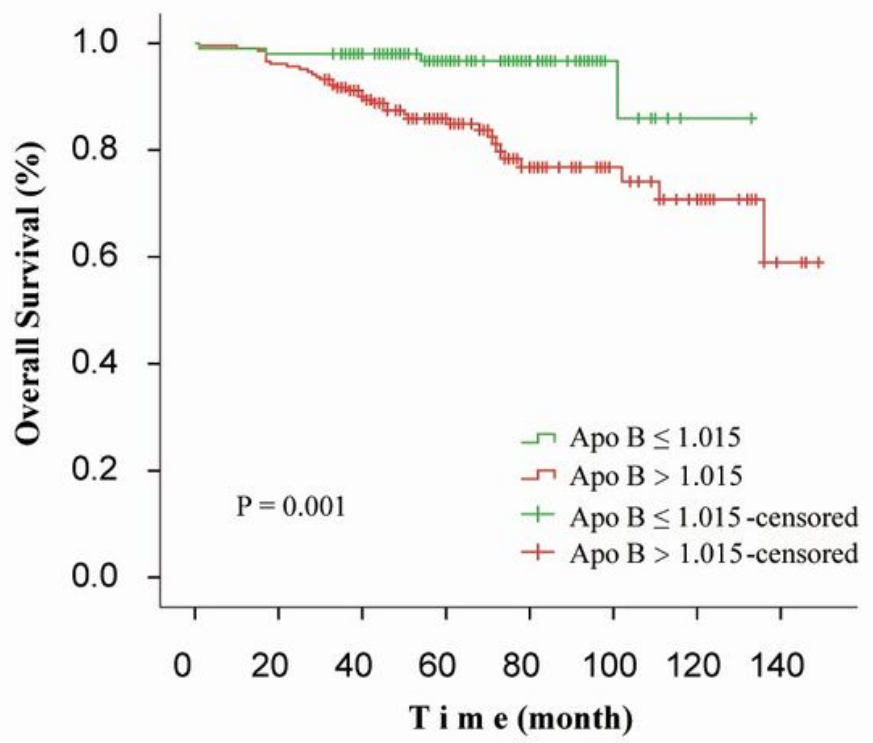

B

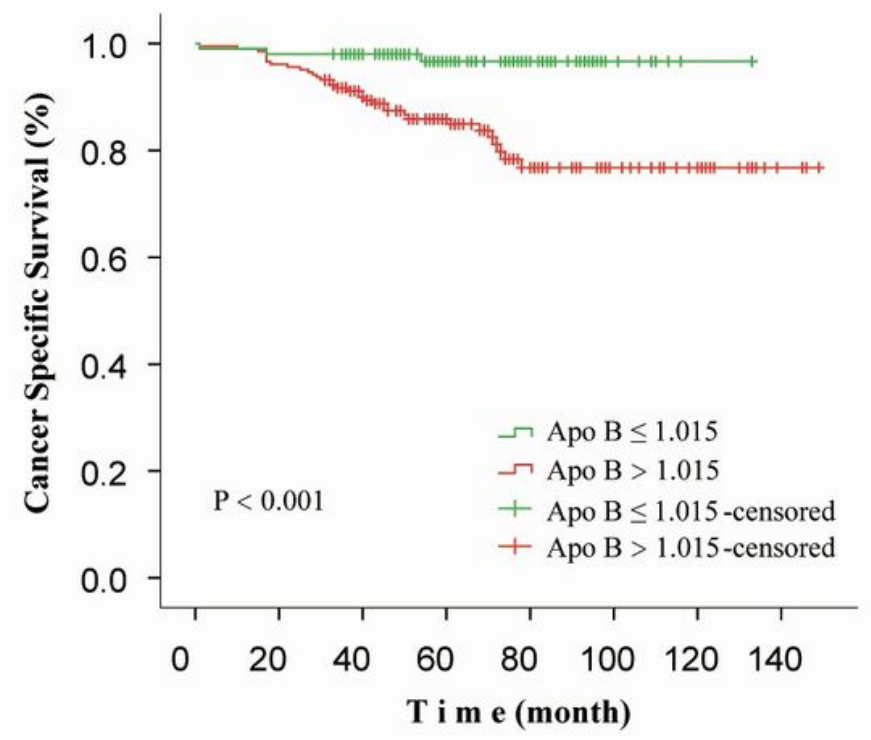

\section{Figure 1}

The Kaplan-Meier survival curves according to the preoperative apolipoprotein B level. The OS and CSS rates were significantly higher in the high $A p o B$ level group compared with the low group $(P=0.001$ and $P<0.001$, respectively). 